\section{Non-paraneoplastic limbic encephalitis associated with NMDAR and VGKC antibodies}

\section{INTRODUCTION}

Limbic encephalitis (LE) is characterised by seizures and impairment of short-term memory as well as behavioural and psychiatric symptoms such as anxiety, depression, personality change and hallucinations. Onset of these symptoms is typically subacute over a few weeks or months but may also evolve over a few days. In many patients, limbic encephalitis is a paraneoplastic syndrome usually preceding diagnosis of the malignancy. Associated tumours are most commonly small-cell lung cancer (SCLC), breast cancer testicular tumour, teratoma, Hodgkin lymphoma and thymoma. ${ }^{1}$ Antineuronal autoantibodies can be detected in the sera of about $60 \%$ of patients. These autoantibodies are classically directed to intracellular antigens (eg, anti-Hu, anti-Ma1/2, anti-CRMP5/CV2, anti-amphiphysin). However, LE is now being recognised frequently in the absence of malignancy and can be associated with antibodies to voltage-gated potassium channel (VGKC-ab). More recently, a new type of immunotherapy-responsive severe LE was described by Dalmau and colleagues that is associated with antibodies to the $N$-methylD-aspartate-receptor (NMDAR) and ovarian teratoma. In rare instances, these NMDAR$\mathrm{ab}$ also occur in men with testicular teratoma or SCLC. ${ }^{2}{ }^{3}$ For the first time, we describe a male patient with non-paraneoplastic limbic encephalitis and with serum antibodies to both NMDAR and VGKC.

\section{CASE REPORT}

This previously healthy 56-year-old man reported the first signs of disease in 2007 when he recognised hypersomnia and progressive generalised myoclonus while sleeping. Additionally, he developed short-term memory loss, concentration deficits and disorientation. All these symptoms evolved over 6 months. At this point of time, the

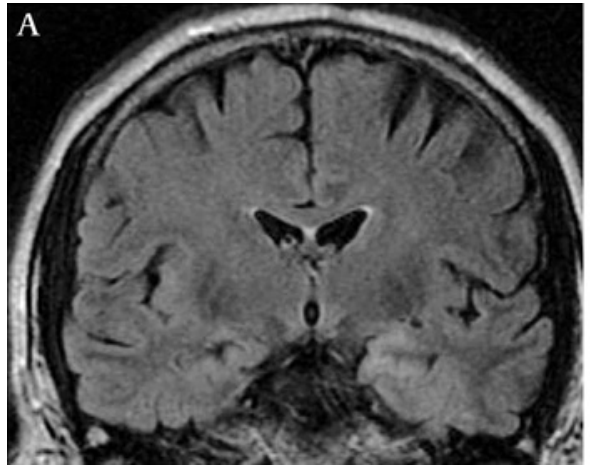

patient experienced his first epileptic seizure. However, there was no evidence for neuromyotonia.

Neuropsychological testing revealed severe verbal amnestic syndrome. MRI of the brain showed bitemporal T2- and fluid-attenuated inversion recovery-hyperintense lesions. There was no evidence of contrast enhancement in the T1-weighted sequences (figure 1). EEG showed diffuse slowing and focal epileptic activity in the left temporal lobe. Repetitive cerebrospinal fluid (CSF) investigations revealed normal values for lymphocytes and protein. Serum and CSF revealed the same oligoclonal IgG bands. Serum analysis showed slight hyponatraemia $(129 \mathrm{mmol} / \mathrm{l})$, which resolved completely during the following weeks. Blood cell count, thyroid function test including thyroid autoantibodies, antibodies to double-stranded DNA, and SSA/Ro and $\mathrm{SSB} / \mathrm{La}$ were unremarkable. Paraneoplastic antineuronal antibodies (Hu, Ri, Yo, Ma1, Ma2, Recoverin, CRMP5/CV2), tumour markers and screening for infectious disease such as, herpes simplex virus IgG and PCR were all negative. Limbic encephalitis was diagnosed according to reviewed diagnostic criteria. ${ }^{4}$ Oral methylprednisolone therapy ( $1 \mathrm{mg} / \mathrm{kg}$ body weight) followed by oral tapering to $5 \mathrm{mg}$ per day led to a marked clinical improvement during the following weeks. Therefore, steroid therapy was continued with this dosage. Seizures were treated with levetiracetam (1 g twice daily) successfully.

One year after onset of symptoms, he was seen in our institute for the first time. We obtained positive results for VGKC-ab at a level of 392 pM (normal $<100$ pM) as well as for NMDAR-ab (scoring 2 on a range from 0 (negative) to 4 (highly positive) (Irani S, Vincent A unpublished results)). Repetitive testing 3 months later confirmed both of these positive results (NMDAR-ab 2; VGKCab $281 \mathrm{pM}$ ). An extensive tumour search including positron emission tomography with fluor-desoxyglucose in combination with CT (FDG-PET/CT) of the whole body did not reveal an underlying neoplasm. Urological examination including ultrasound of the testis gave no evidence for testicular cancer.

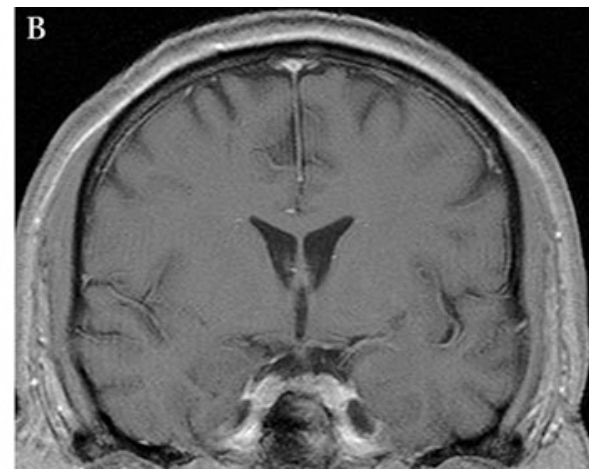

Figure 1 Brain MRI findings at onset of symptoms. (A) Fluid-attenuated inversion recovery showing hyperintensity asymmetrically involving both medial temporal lobes. (B) Contrastenhanced T1 images. No gadolinium uptake was shown. 
Brain MRI revealed complete remission of the right temporal lobe lesion and partial remission of the lesion in the left temporal lobe. In order to reduce steroids, persistent cognitive deficits, and still raised antibody titres, treatment with azathioprine was initiated. With this therapy, the patient has remained stable until now with slight residual memory deficits but returned to work recently. During therapy with levetiracetam, there is no evidence of seizures. However, long-term follow-up is needed.

\section{DISCUSSION}

Here, we report a male patient with nonparaneoplastic VGKC-ab and NMDAR-ab associated limbic encephalitis. While the mere occurrence of NMDAR-ab in male patients is relatively rare and limited to a few cases worldwide, to our knowledge this is the first patient to harbour both VGKC-ab and NMDAR-ab.

In patients with VGKC-ab associated LE, clinical improvement is associated with titre reduction. Since first testing for both antibodies occurred 1 year after the onset of symptoms and 6 months after the start of steroid therapy, we cannot determine the decline of the antibody titre after therapy. However, both antibodies were still present at this time and also detectable 6 months later.

While most patients with VGKC-abassociated limbic encephalitis present with a subacute amnesic syndrome, seizures and REM sleep behaviour disorder and do not have an underlying malignancy, ${ }^{5}$ NMDARab-associated limbic encephalitis usually affects young women with an ovarian teratoma. ${ }^{2}$ These patients usually present with acute, severe psychiatric symptoms including personality change, paranoia, anterograde amnesia, agitation and/or catatonic stupor. Autonomic symptoms and central hypoventilation as well as seizures may also be present in NMDAR-ab positive cases. Most of these patients have lymphocytes in CSF, while VGKC-ab-associated LE usually lacks CSF changes.

The majority (85\%) of previously described patients suffering from NMDAR$\mathrm{ab}$ associated LE had prodromal flu-like illness; ${ }^{3}$ however, our patient did not have such symptoms, had a more insidious disease progress and had no evidence for the presence of an underlying tumour. Clinical presentation was more similar to VGKC-ab associated LE than NMDAR-ab associated LE. In our experience, none of the 60 control patients were positive for antibodies to NMDAR, and all patients with these antibodies have an encephalitic illness (Irani and Vincent unpublished results), so this test seems to be specific.

This case emphasises the importance of testing for antibodies in patients with subacute onset of encephalopathy and suggests that the clinical spectrum of NMDAR-ab and VGKC-ab associated LE may turn out to be broader than initially described. Since both types of LE are associated with excellent treatment responses, and since the extent of residual symptoms correlates with time of treatment initiation, it is important to recognise and treat autoimmune limbic encephalitis early during disease course.

Hannah L Pellkofer, ${ }^{1,2}$ Tania Kuempfel, ${ }^{1}$ Leslie Jacobson, ${ }^{3}$ Angela Vincent, ${ }^{3}$ Tobias Derfuss ${ }^{1,4}$

${ }^{1}$ Institute of Clinical Neuroimmunology, Ludwig Maximilians University, Munich, Germany;

${ }^{2}$ Department of Neurology, Ludwig Maximilians University, Munich, Germany; ${ }^{3}$ Weatherall Institute of Molecular Medicine, John Radcliffe Hospital, University of Oxford, Oxford, UK; ${ }^{4}$ Department of Neurology, University of Erlangen-Nuremberg, Erlangen, Germany

Correspondence to Dr Hannah Pellkofer, Institute of Clinical Neuroimmunology, Ludwig Maximilians University of Munich, Marchioninistr. 15, Munich D-81377, Germany; hannah.pellkofer@med. uni-muenchen.de

Competing interests HP and TK have received personal compensations from Bayer Schering Pharma, Teva, Merck-Serono and Biogen Idec.

TD has received personal compensations from Bayer Schering Pharma, Novartis, Merck-Serono and Biogen Idec.

Patient consent Obtained.

Provenance and peer review Not commissioned; externally peer reviewed.

Received 18 June 2009

Revised 24 September 2009

Accepted 25 September 2009

Published Online First 28 July 2010

J Neurol Neurosurg Psychiatry 2010;81:1407-1408. doi:10.1136/jnnp.2009.186494

\section{REFERENCES}

1. Darnell RB, Posner JB. Paraneoplastic syndromes involving the nervous system. $N$ Engl J Med 2003;349:1543-54.

2. Dalmau J, Tüzün $\mathrm{E}, \mathrm{Wu} \mathrm{H}$, et al. Paraneoplastic anti- $\mathrm{N}$-methyl-D-aspartate receptor encephalitis associated with ovarian teratoma. Ann Neurol 2007:61:25-36.

3. Dalmau J, Gleichman AJ, Hughes EG, et al. AntiNMDA-receptor encephalitis: case series and analysis of the effects of antibodies. Lancet Neurol 2008;7:1091-8.

4. Graus F, Saiz A, Lai M, et al. Neuronal surface antigen antibodies in limbic encephalitis: clinical-immunologic associations. Neurology 2008;71:930-6.

5. Vincent A, Buckley C, Schott JM, et al Potassium channel antibody-associated encephalopathy: a potentially immunotherapyresponsive form of limbic encephalitis. Brain 2004:127:701-12. 


\section{JNNP}

\section{Non-paraneoplastic limbic encephalitis associated with NMDAR and VGKC antibodies}

Hannah L Pellkofer, Tania Kuempfel, Leslie Jacobson, et al.

$J$ Neurol Neurosurg Psychiatry 2010 81: 1407-1408 originally published online July 28,2010

doi: 10.1136/jnnp.2009.186494

Updated information and services can be found at:

http://jnnp.bmj.com/content/81/12/1407.full.html

\section{These include:}

References This article cites 5 articles, 2 of which can be accessed free at: http://jnnp.bmj.com/content/81/12/1407.full.html\#ref-list-1

Article cited in:

http://jnnp.bmj.com/content/81/12/1407.full.htmI\#related-urls

Email alerting Receive free email alerts when new articles cite this article. Sign up in service the box at the top right corner of the online article.

Notes

To request permissions go to:

http://group.bmj.com/group/rights-licensing/permissions

To order reprints go to:

http://journals.bmj.com/cgi/reprintform

To subscribe to BMJ go to:

http://group.bmj.com/subscribe/ 